\title{
BENCHMARK FOR NUMERICAL ANALYSIS OF STEEL AND COMPOSITE FLOORS EXPOSED TO FIRE USING A GENERAL PURPOSE FEM CODE
}

\author{
Ioan Both \\ Czech Technical University in Prague, Czech Republic \\ František Wald \\ Czech Technical University in Prague, Czech Republic \\ Raul Zaharia \\ Politehnica University of Timisoara, Romania
}

Increasing number of tests on structures in fire conditions offers valuable information regarding the global and local behaviour. The output data of these experiments can be considered to be a good opportunity for validation of numerical models. Nevertheless, in some fortuitous cases, inaccurate input of numerical models may lead to results matching the experimental ones. The validation and/ or verification of advanced calculation models for the fire design are an important issue not only for computer code developers, but also for designers and authorities. The validation of an advanced calculation model is usually linked with the comparison to experimental results, while the verification is related to the comparison to analytical solutions or to the results given by other computer codes. The paper presents a benchmark for both thermal and structural analysis of a composite floor subjected to fire using beam and shell elements. The numerical analysis is performed with a general purpose finite-element code. The input and the output of the thermo-mechanical analysis are detailed, with respect to a real scale fire test.

Keywords: Benchmark, Fire design, Composite slab, Numerical analysis, Experimental analysis

\section{INTRODUCTION}

The purpose of the first fire tests was to demonstrate that the structural elements can fulfil the prescriptive demands for fire security, according to national regulations. A greater extent of experimental data from fire tests on full scale structures has been presented in the last two decades. The development of the technology led to equipment able to record information at high temperatures which promoted an enlarged output data from the fire tests, allowing a more accurate understanding of structural and thermal response of structures.

Since the Eurocodes [08], [07], accepted the advanced calculation models for the structural design in fire situations, the verification and the validation of the computer programs became an important topic. In principle, the validation of an advanced calculation model is based on the comparison with experimental results. It is stated in the Eurocodes that the advanced calculation models should be validated by comparison with relevant test results, and the critical parameters shall be checked by means of a sensitivity study. On the other hand, there is always the possibility of verification for a numerical model, through the comparison to analytical solutions or to other computer codes.

Generally, the numerical analysis of the structures subjected to thermal load requires a large amount of resources. General purpose software [01], [02] are suitable for the structural analysis of structures subjected to elevated temperatures, but they require the definition of all the parameters needed in such analysis; a solution for this inconvenience is the use of dedicated software for fire design [11], [19].

One of the common definitions states that a benchmark is a standard or reference by which others can be measured or judged [10]. In order to support and reproduce a benchmark, input and output data should be presented in detail as recommended and performed in Wald et al. [20]. 
Considering these aspects, the paper presents a procedure to be followed within a thermo-mechanical numerical analysis of a composite slab, using the general purpose software Abaqus [01]. The benchmark for verification purpose is based on the data from a full scale fire test of a composite steel and concrete slab [22], [23]. In order to produce an accessible benchmark, some features that need to be introduced in the numerical model are considered in a simplified manner. Complete input data, with all necessary parameters to be accounted for a thermo-mechanical numerical analysis of a structure in fire

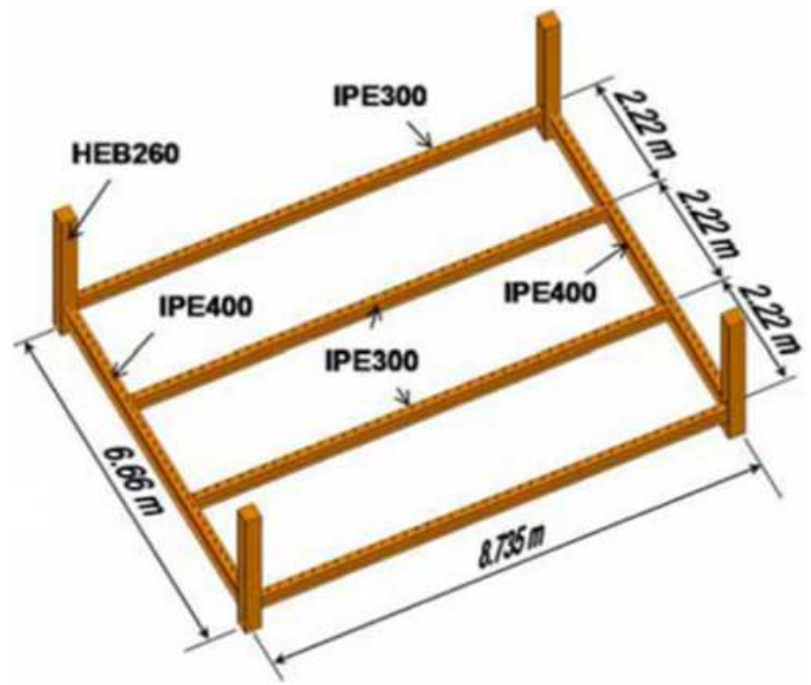

conditions, are also considered within a supplementary validation analysis. The validation is performed considering the outcome of the real scale fire test on the composite slab, in order to prove that the suggested numerical procedure is able to lead to correct results.

\section{REFERENCE STRUCTURE}

The input of the benchmark is based on the full scale fire test FRACOF [22],[23], made for a steel and concrete composite floor of more than 60 $\mathrm{m} 2$. The geometry of the composite floor and the structural elements are presented in Figure 1.

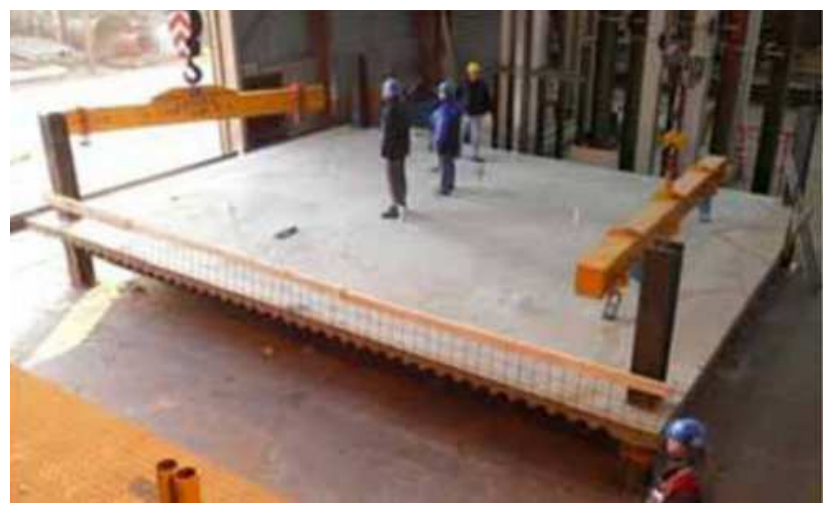

Figure 1: Test setup of FRACOF fire test [11] a) steel elements grid, b) composite floor

At each corner of the slab, a HEB260 column of $0.8 \mathrm{~m}$ height was provided.

S355 steel grade was used for the primary beams, S235 for the secondary beams and S500 for the reinforcement. The connections between structural elements were designed as flexible end plates for primary beams and double angle web cleats for the secondary beams. Headed studs were used in order to provide a full interaction between the concrete slab and the steel beams. The position of studs was chosen according to the steel sheet ribs, Cofraplus60-0.75 mm. The structural details are also available on the website of the RFCS project - MACS+ [16].

The elevated temperatures during the fire test followed the nominal standard fire curve. All edge beams were protected, while the two interior secondary beams were directly subjected to gas temperature.

\section{BENCHMARK MODEL}

Benchmarks represent simple models that should disseminate the guidelines and the results of an analysis. Different mathematical formulations may be used to create a numerical model in the general purpose computer FEM code Abaqus, i.e. static or dynamic. In the following are presented the necessary steps for a static thermomechanical analysis of the considered composite steel and concrete slab.

\section{Inputs}

Although real materials have temperature dependent material properties, for simplicity of the benchmark, only some of the mechanical properties are considered to alter their characteristics function of temperature.

\section{Thermal properties}

The values of the thermal properties considered for steel and concrete within the benchmark are given in Table 1. 
Table 1. Thermal properties

\begin{tabular}{|c||c|c|c|}
\hline Material & $\begin{array}{c}\alpha \\
{[1 / 0 \mathrm{C}]}\end{array}$ & $\begin{array}{c}\text { Thermal } \\
\text { conductiv- } \\
\text { ity } \\
{[\mathrm{W} / \mathrm{m} \mathrm{K}]}\end{array}$ & $\begin{array}{c}\text { Specific } \\
\text { heat } \\
{[\mathrm{J} / \mathrm{kg} \mathrm{K}]}\end{array}$ \\
\hline \hline Steel & $1.4 \mathrm{E}-5$ & 40 & 550 \\
\hline Concrete & $1.0 \mathrm{E}-5$ & 0.9 & 1050 \\
\hline
\end{tabular}

\section{Mechanical properties}

The benchmark will consider the material properties specified in Table 2 and Table 3.

Table 2. Mechanical properties of steel

\begin{tabular}{|c|c||c|c|}
\hline Material & $\begin{array}{c}\mathrm{E} \\
{[\mathrm{N} / \mathrm{m} 2]}\end{array}$ & $v$ & $\begin{array}{c}\text { fy } \\
{[\mathrm{N} / \mathrm{m} 2]}\end{array}$ \\
\hline S235 & $2.1 \mathrm{E} 11$ & 0.3 & $235.0 \mathrm{E} 6$ \\
\hline S355 & $2.1 \mathrm{E} 11$ & 0.3 & $355.0 \mathrm{E} 6$ \\
\hline \hline S500 & $2.1 \mathrm{E} 11$ & 0.3 & $500.0 \mathrm{E} 6$ \\
\hline
\end{tabular}

Table 3. Mechanical properties of concrete

\begin{tabular}{|l|c|c|c|c|}
\hline Material & $\begin{array}{c}\mathrm{E} \\
{[\mathrm{N} / \mathrm{m} 2]}\end{array}$ & $v$ & $\begin{array}{c}\mathrm{fc} \\
{[\mathrm{N} / \mathrm{m} 2]}\end{array}$ & $\begin{array}{c}\mathrm{ft} \\
{[\mathrm{N} / \mathrm{m} 2]}\end{array}$ \\
\hline Concrete & $3.3 \mathrm{E} 10$ & 0.2 & $30.0 \mathrm{E} 6$ & $3.0 \mathrm{E} 6$ \\
\hline
\end{tabular}

As mentioned above, for simplicity, the properties were considered to be constant, with the values corresponding to ambient temperature of $200 \mathrm{C}$.

The mechanical properties presented in the above tables serve as the reference nominal values for ambient temperature. The reduction coefficients of the mechanical properties for elevated temperature are considered as specified in EN 1994-1-2 [07], taking into account different coefficients for the structural steel used for beams (S355 for primary beams and S235 for secondary beams) and for reinforcing steel (S500).

For the structural analysis in Abaqus, the elastic-perfect plastic model considered for steel is defined by the Young's modulus (considered for this benchmark as not dependent of temperature), and the effective yield strength fy, $\theta$, determined for different temperatures according to the EN 1994-1-2 [02]. The elastic-perfect plastic model considered for concrete model is defined by Young's modulus (considered for this benchmark as not dependent of temperature), the compressive strength $\mathrm{fc}, \theta$, the tensile strength fck,t, $(\theta)$, determined for different temperatures according to the EN 1992-1-2 [12]. The concrete model uses the value 12 for Dilation Angle while the other data are chosen by default. The concrete damaged plasticity considered in Abaqus allows the definition of different behaviour for compressive and tensile stresses.

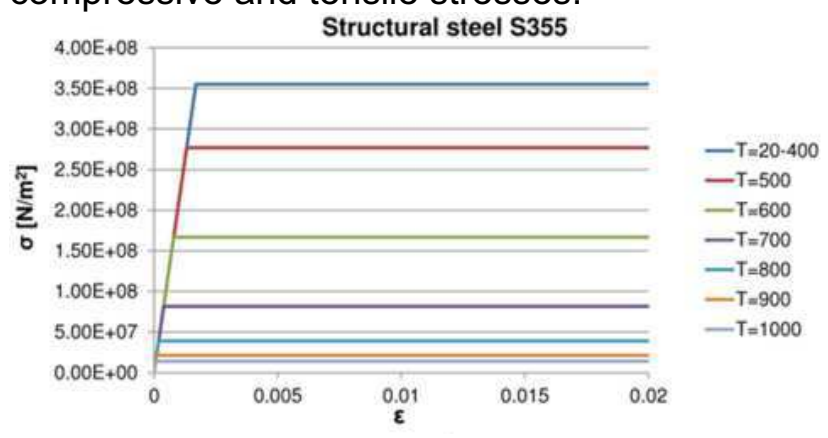

(a)

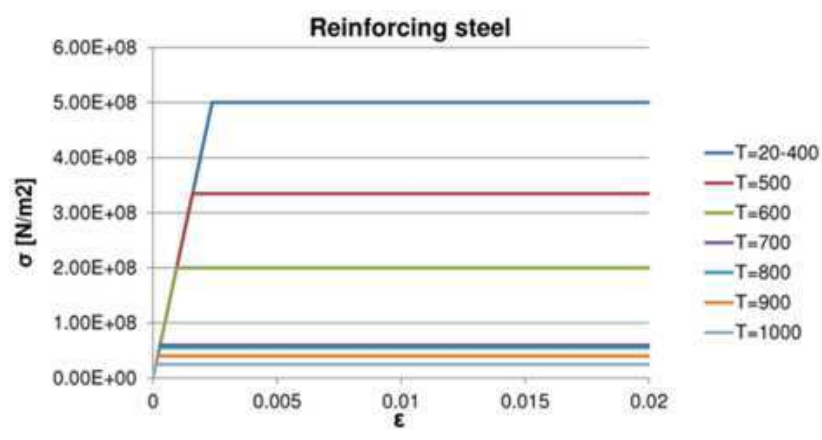

(b)

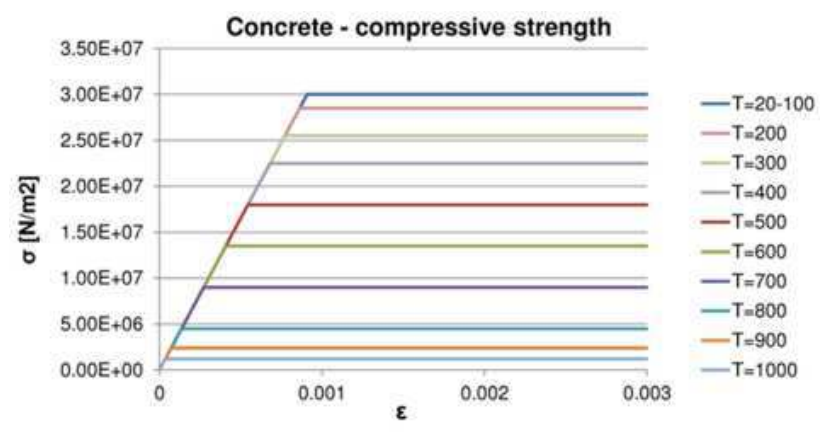

(c)

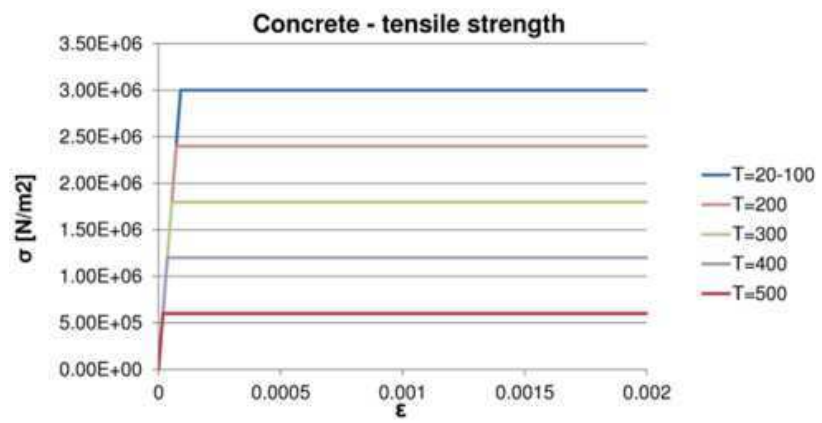

(d)

Figure 2: Simplified mechanical properties a) structural steel S355, b) reinforcing steel, c) compressive strength of concrete, $d$ ) tensile strength of concrete 
Figure 2 shows the simplified material properties function of temperature.

The numerical analysis also requires the definition of the steel and the concrete density. The values were defined as $7850 \mathrm{~kg} / \mathrm{m} 3$ and 2400 $\mathrm{kg} / \mathrm{m} 3$, respectively.

\section{Thermal load}

Temperature field definition in structural elements is presented in literature in different manners [8], [13]. This benchmark presents the definition of temperatures in beams and slab in three modes: constant temperature for the unprotected beams, gradients through protected beams section and imported temperature field for slab.

For the heat transfer analysis under nominal standard fire curve, the temperatures at the surface of the elements are transferred from the hot gases by convection and radiation considering the convective heat transfer coefficient and the emissivity as $25 \mathrm{~W} / \mathrm{m} 2 \mathrm{~K}$ and 0.7 , respectively, according to EN1991-1-2 [14]. The numerical model for heat transfer analysis is presented in Section 2.2.1.

\section{Mechanical load}

The test was performed by loading the slab with sand bags for an equivalent uniform distributed load of $3870 \mathrm{~N} / \mathrm{m} 2$ [09], [10]. In addition to this load, the numerical model has to consider the self-weight of slab and beams, leading to a total uniform distributed load on the slab of 7150 $\mathrm{N} / \mathrm{m} 2$

\section{Model}

\section{Thermal analysis}

An important aspect when dealing with a general purpose software is the correct setting of the physical constants. In Abaqus, for a thermal analysis which considers Celsius degrees, the Absolute zero temperature should be set to -273.15 , and the Stephan-Boltzmann constant must be defined at the value of $5.67 \mathrm{e}-8$.

A 2D transient heat transfer analysis is performed in order to obtain the temperature evolution in time. The temperature field distribution for the IPE300 beam section was obtained using DC2D4 finite elements in a transient heat transfer step of $7200 \mathrm{~s}$ and a maximum increment size of $5 \mathrm{~s}$. The interactions needed to be defined are the surface film coefficient and the surface radiation. For convection, a constant embedded film coefficient of 25 is defined with the sink temperature of 1 and the amplitude defined as a tabulated data corresponding to the fire curve. For radiation, a constant emissivity of 0.7 is defined, with the ambient temperature of 1 and the amplitude of ambient temperature defined in a similar manner as for convection. The interactions are defined on the exposed faces of the secondary beams sections.

Protected beams involve an increased degree of difficulty for thermal analysis since the exact thermal properties of insulation material are temperature dependent and vary with the type of insulation. Thermal properties for insulation material may be taken from examples presented in the work of Kruppa and Zhao [14] and Zaharia et al. [21]. In the output of the real test, [22], [23], the temperature distribution on the cross section varies from $150 \mathrm{OC}$ to $300 \mathrm{OC}$. This paper will consider the temperatures from the test since it intends to present the thermal load as a gradient through the beam section.

The temperature gradient is generally defined as the temperature increase over the unit of distance. Abaqus considers a different approach, especially for linear elements defined function of the reference line of the cross-section. In steel and concrete composite structures, the reference line of a beam element may be translated, so that the numerical model corresponds to the geometry of the real structure.

In order to obtain the gradient over the beam cross section, the temperature of the reference line must be computed first. Considering the primary beam reference line at the level of the slab middle plane (Fig. 3), it results a value of 114.4 $\mathrm{OC}$ by linear interpolation. The thermal gradient is given by the following equation:

$$
\theta_{\text {ref }}\left(1+d_{2} \cdot x\right)=\theta_{2}
$$

where: Өref - temperature at reference line level, $\mathrm{d} 2$ - distance from reference line to a point along direction 2; $\theta 2$ - temperature at distance d2.

Considering the effective thickness of the slab and the relative position of the slab with respect to top surface, the input in Abaqus for the IPE400 protected beam should result in the following data: reference magnitude 1 , tabulated amplitude of $200 \mathrm{C}$ at $0 \mathrm{~s}$ and $114.4 \mathrm{OC}$ at 7200 $\mathrm{s}$, gradient along direction 1 of 0 and gradient along direction 2 of -3.2757 . 


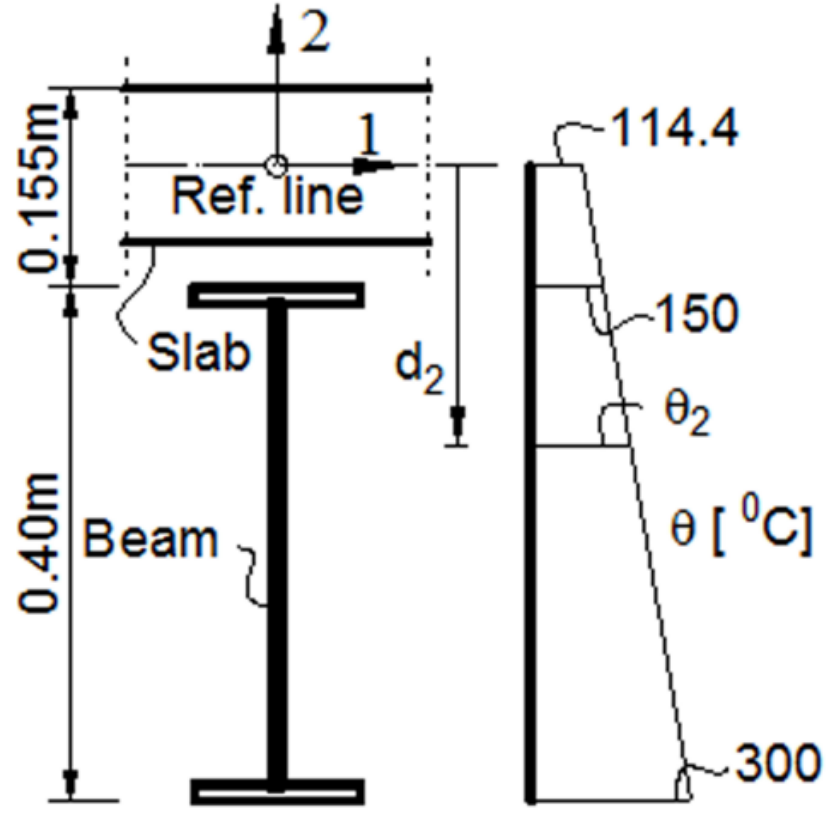

Figure 3: Protected beam temperature distribution

Similar calculations should be done for the IPE300 protected beam.

The thermal analysis of the slab is performed in a separate numerical model. The temperature field resulted from this analysis is used as an input file for the structural analysis. The coordinates of the elements are important, and should be the same in both thermal and structural analysis. A common procedure is to create the slab model for the thermal analysis and then to save it as a different model for the structural analysis.

The slab is divided into areas delimited by the secondary beams, and planar shell elements of DS4 type are assigned. The thickness of the slab is considered constant, with an effective thickness of $0.12 \mathrm{~m}$, according to EN 1994-1-2 [07]. The cross section of the slab is defined with Simpson integration rule having 13 integration points. A transient heat transfer step is created for a time interval of $7200 \mathrm{~s}$ with a maximum increment of $5 \mathrm{~s}$.

Heat transfer considers convection and radiation on both heated and unheated side of the slab. For the heated side, convection is defined as a constant surface film coefficient of $25 \mathrm{~W} / \mathrm{m} 2 \mathrm{~K}$, a sink temperature of 1 , and sink amplitude according to the nominal standard fire curve. Radiation on heated side considers an emissivity factor of 0.7 and the same sink temperature and amplitude as for convection. The unheated side interacts with the environment through a coefficient of heat transfer by convection of $4 \mathrm{~W} / \mathrm{m} 2 \mathrm{~K}$ and an emissivity of 0.7 . For both cases, the sink temperature is $200 \mathrm{C}$. A predefined field for initial temperature of $200 \mathrm{C}$ is considered.

In section 4.3, EN1992-1-2 [06] states that the temperature profile in a reinforced concrete element may be assessed omitting the presence of the reinforcement, and therefore the thermal model does not include the definition of reinforcement. The temperatures of the reinforcement needed for the structural analysis are considered as the temperatures of the concrete, on the corresponding position of the reinforcement.

\section{Structural analysis}

The numerical model of a structural analysis in Abaqus starts from the geometry defined for the slab in the thermal model. In this way, the temperature field can be imported and used as an input data for the structural analysis. The structural model includes the reinforcement mesh in the concrete slab. The reinforcement mesh $\Phi 7 / 150$ is defined as a smeared layer at level $0.01 \mathrm{~m}$ with respect to the slab middle plane, which corresponds to the real position of the reinforcement in the cross-section of slab. It has to be specified that the previous element type considered for the slab in the Abaqus thermal analysis, must be modified to an S4 general purpose shell element for the structural analysis.

The steel beams are defined in Abaqus as 3D planar Wire to whom B31 type 2-node linear beam elements are assigned. This type of element requires profile definition for each crosssection type. The profiles are constructed with respect to a defined reference line. The reference line of both primary and secondary beams should consider the real height of slab as shown in Figure 3.

Computation is performed in Abaqus in two separate General Static steps, considering the nonlinear effects of large deformations. The first step is defined for applying the mechanical load specified in Section 2.1.4. The second step is defined for a $7200 \mathrm{~s}$ with a maximum increment of $5 \mathrm{~s}$, as considered for thermal analysis. Within this step, the temperatures are defined. For the unprotected beam, a Constant temperature field with tabular amplitude obtained from the thermal analysis of IPE300 as presented in Section 2.2.1, was applied. The protected beam predefined temperature field is separately defined as gradients through the beam section, with the values presented in Section 2.3.1. The 
temperature field of the slab is imported from the output data base of the thermal analysis of slab performed according to Section 2.2.1. An initial temperature of $200 \mathrm{C}$ should be also specified in a temperature Predefined field.

The pinned columns and the horizontal restrain on one of the short edges of the slab [16] represent the support conditions of the composite slab.

The beam-to-column conditions are modelled by connectors of JOIN type, which constrain only the translational degrees of freedom. This implies that all the connections between linear elements are supposed to be hinged.

It was shown that the analysis considering different levels of interaction between slab and beams may lead to different results, but the full interaction exhibit values closer to real experiment [13]. The connectors between beams and slabs should be placed according to the real distribution of the studs, leading to a complex numerical model, inappropriate for the purpose of this benchmark study. Therefore, the slab and the beams are considered in full interaction, by defining a TIE type constraint, which includes the rotational degrees of freedom.

The numerical model created for the structural analysis consisted in a two steps analysis. The first step was defined for the mechanical loading which was propagated in the second step. The temperatures of all elements were introduced in the second step as Predefined fields. Both steps were considered to be Static, general.

\section{OUTPUTS}

\section{Results}

Since the results recorded for the FRACOF test are temperatures, displacement in the center of the slab and displacements of beams, the discussion is focused on these quantities.

The unprotected beam exhibits a temperature distribution with very small gradients, and thus it may be considered to be uniform. Temperatures obtained in beam's web (Figure 4a) are used as a predefined field for the entire structural model in a tabular form in Abaqus.

For the protected steel beams, the temperature evolution for the bottom and top flange is given in Figure 4b.

Following the heat transfer analysis of the slab, the nodal temperatures NT obtained in Abaqus are presented in Figure 5 (13 points were de- fined on the thickness of the slab for the thermal analysis).

The displacements for the central point of the slab, unprotected beams, secondary protected beams and primary protected beams are presented in Figure 6, function of the time and of the temperatures of nominal standard fire curve.

\section{Mesh sensitivity study}

Different results are obtained as a consequence of finite element size definition, while numerical formulation or element type may also reveal different results [15].

Several mesh dimensions of the slab were considered for the sensitivity study, the size of the elements in Table 4 being an approximate value. The present benchmark, as well as the parameters calculated in Table 4, follows the recommendations given in some examples of sensitivity studies [15], [09]. The monitored variable for this study is the vertical displacement of the center point of the slab (U3). It is to be mentioned that mesh sizes larger than the ones provided in Table 4 lead to numerical problems which crashed the analysis before reaching the final time step.

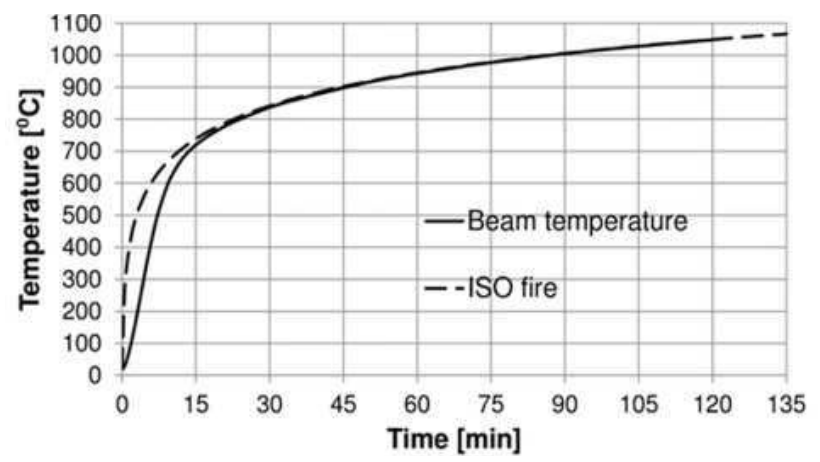

(a)

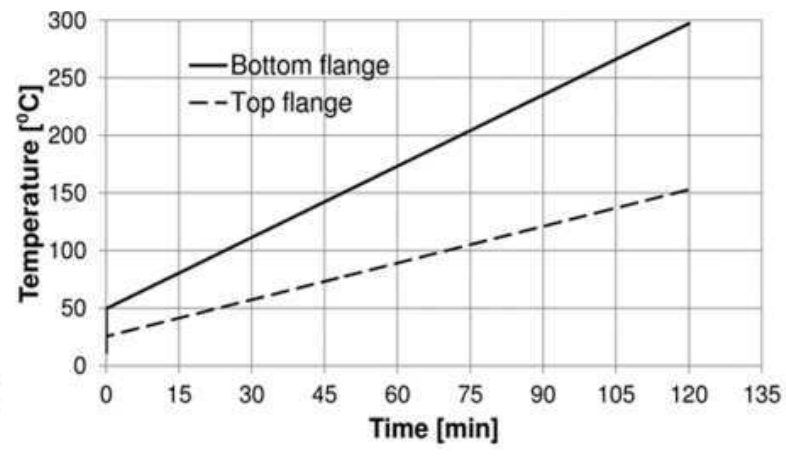

(b)

Figure 4: Temperature field a) unprotected beam b) protected beams 


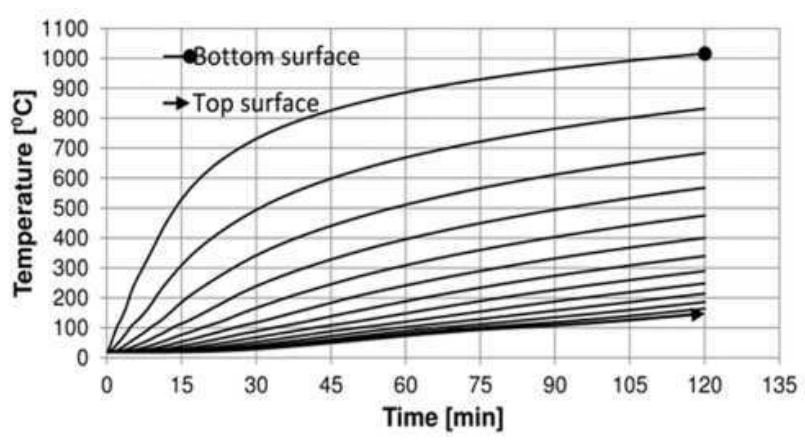

(a)

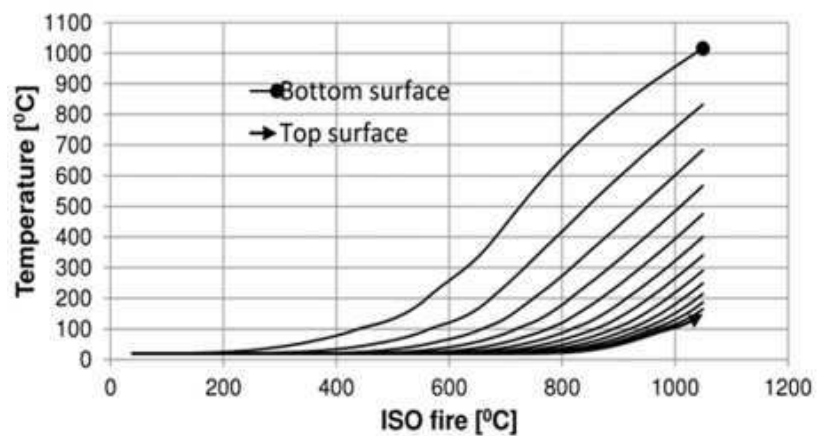

(b)

Figure 5: Temperature field in the slab function of: a) time, b) standard fire

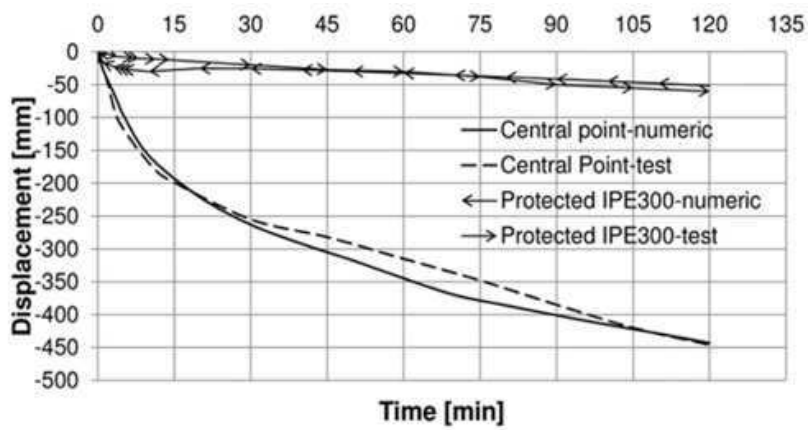

(a)

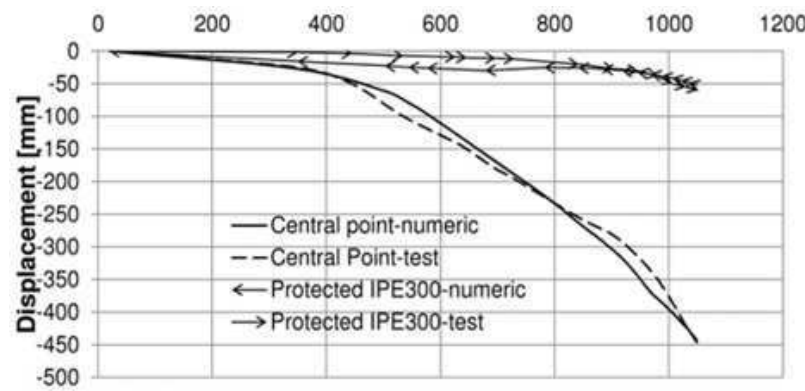

ISO fire $\left[{ }^{\circ} \mathrm{C}\right]$

(b)

Figure 6: Vertical displacement function of: a) time, b) standard fire

Table 4: Mesh sensitivity study

\begin{tabular}{|c|c|c|c|c|c|c|c||c|c|c|c|c|}
\hline & $\begin{array}{c}\text { Size } \\
{[\mathrm{m}]}\end{array}$ & $\begin{array}{c}\text { Variable: } \\
\text { U3 }[\mathrm{cm}]\end{array}$ & $\begin{array}{c}\text { Grid: } \\
\mathrm{h}\end{array}$ & Ftor $\mathrm{r}$ & $\varepsilon$ & $\begin{array}{c}\text { Apparent } \\
\text { order: } \\
\mathrm{p}\end{array}$ & $\begin{array}{c}\text { Asympt } \\
\text { solution }\end{array}$ & $\begin{array}{c}\text { Extra- } \\
\text { polated } \\
\text { value }\end{array}$ & $\begin{array}{c}\text { Approximate } \\
\text { relative error }\end{array}$ & $\begin{array}{c}\text { Extrapo- } \\
\text { lated } \\
\text { relative } \\
\text { error }\end{array}$ & $\begin{array}{c}\mathrm{GCl} 12 \\
{[\%]}\end{array}$ & $\begin{array}{c}\mathrm{GCl} 23 \\
{[\%]}\end{array}$ \\
\hline 1 & 0,3 & 42.03 & 0.304 & 1.262 & -0.27 & & & 42.20 & 0.0064 & 0.0039 & & \multirow{2}{*}{0.84} \\
\hline 2 & 0,4 & 41.76 & 0.383 & - & - & 4.160 & 42.20 & - & - & - & 0.49 & 0.84 \\
\hline 3 & 0,5 & 41.05 & 0.519 & 1.354 & -0.71 & & & 42.04 & 0.0170 & 0.0067 & & \\
\hline
\end{tabular}

The representative value $h$ is computed using equation (2) for the slab, by dividing the area of the slab to the total number of elements function of the mesh size N. The other coefficients are computed as presented in the above mentioned references.

$$
h=\left[\frac{1}{N} \sum_{i=1}^{N}\left(\Delta A_{i}\right)\right]^{1 / 2}
$$

Due to the connection between slab and beams, the size of the beam elements follows the values of the slab elements. The chosen grids respect the conditions of having an approximately constant refinement ratio $r$.

The conclusion that can be drawn from Table 4 is that the numerical uncertainty due to mesh size for the $0.3 \mathrm{~m}$ mesh is in the range of $0.5 \%$, which is considered to be a good value.

\section{VALIDATION}

The numerical model created for validation considers the same mesh, element types, support and element connection conditions as the model used for the benchmark. The temperature field in the elements was also introduced in a similar manner.

On the other hand, the numerical model created for validation considers the experimentally determined mechanical properties of the materials for the FRACOF test [22], [23], while all the thermal and the mechanical properties of the materials are temperature dependent.

For both steels, Young modulus is temperature dependent and the stress-strain relationships 
consider the proportionality limit and the decreasing branch according to EN 1994-1-2 [07].

The concrete compressive response is defined for the two ranges specified in EN 1994-1-2 [07] and the decreasing branch has a linear pattern to the strain $\varepsilon c E$ defined in Annex B of EN 1994-1-2 [07] from which the elastic strains were subtracted. The tensile strength (10\% of the compressive strength at ambient temperature) of concrete is linearly reduced to zero at $6000 \mathrm{C}$. For each temperature, the cracking stress is considered to be reached elastically and the decreasing branch is defined by two points: half of the tensile strength with a strain of $0.2 \%$ and 0 for a strain of $2 \%$.

Thermal expansion has an important influence on the structural behaviour, and it was considered with a constant value within the benchmark. For validation, the expansion coefficient was introduced in Abaqus according to the equations given in EN1994-1-2 [07] and computed accord- ing to the method presented in Both et al. [20]. Abaqus considers the computation of thermal expansion with respect to a reference value, which was set to $200 \mathrm{C}$.

Figure $7 \mathrm{a}$ shows a good correlation with the recorded displacements during the fire test, while Figure $7 \mathrm{~b}$ presents the displacements with respect to nominal standard fire curve. A noticeable difference appears for the protected beams in the first part of simulation. This is caused by the thermal gradient over the beam section which has a constant value over time in numerical simulation, while in the beginning of the test the protected beams are not significantly affected by the temperature increase. Figure 8 presents the deformed shape of the numerical model after $7200 \mathrm{~s}$.

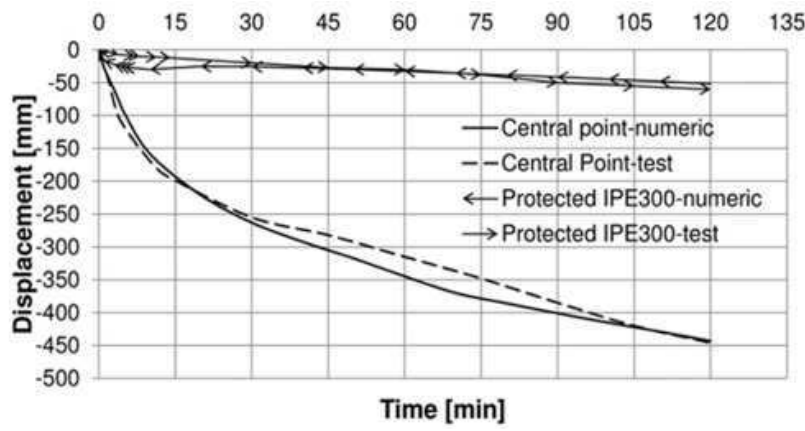

(a)

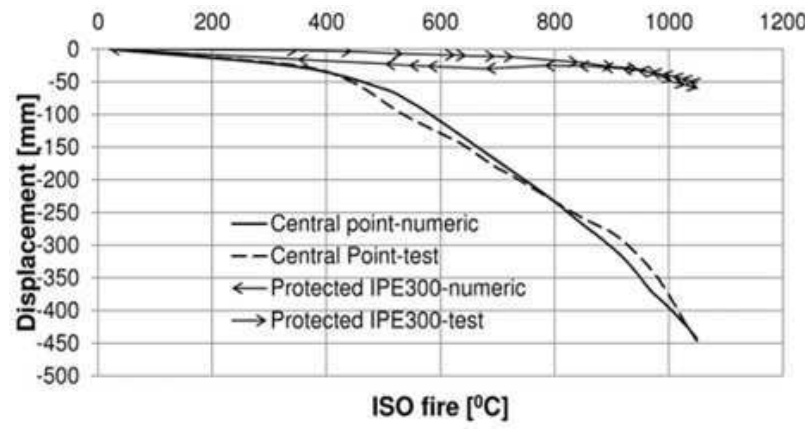

(b)

Figure 7: Displacements recorded by test and numerical analysis function of: a) time, b) standard fire temperature

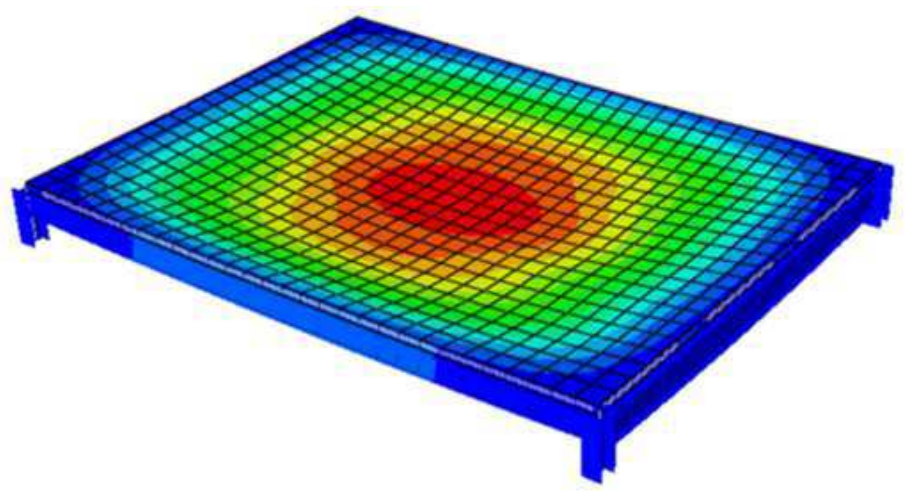

Figure 8: Deformed shape of slab (scale 1:1)

\section{DESIGN VERIFICATION ASPECTS}

Fire design of structures requires the following criteria to be fulfilled [18]:

1) Stability: the ability of an element to maintain the load bearing capacity;

2) Insulation: the ability to resist excessive heat transfer;

3) Integrity: the ability to resist the penetration of flames and hot gases. 
Only the first two criteria may be compared in an advanced model using the FEM results. The stability criterion is estimated from the structural analysis of the structure and the insulation criterion may be verified from the thermal analysis results.Following the full large scale tests, recommendations for design have been offered in the report of the European project "Design tools for the behaviour of fire exposed multi-storey steel framed buildings" [18]. For the numerical analysis, the structural response of the steel-concrete composite slabs should be evaluated function of the maximum displacements and of the tensile plastic strains in the reinforcement.

One condition for failure is that the displacement of a floor beam exceeds the span divided by 20 [18]. This displacement has to be considered with respect to the supports, not to the absolute value. Fig. 9a depicts the relative displacement of beam and the limitation regarding the discussed failure criterion.

According to the simple design method available for composite steel and concrete slabs subjected to fire considering the membrane effect [03], the maximum slab deflection is limited to the value

$$
w=\frac{\alpha\left(\theta_{2}-\theta_{1}\right) \cdot l^{2}}{19.2 \cdot h}+\frac{l}{30}
$$

obtained from relation (3):

where: $w$ - slab deflection; $\alpha$ - coefficient of thermal expansion of concrete; $\theta 2$ - temperature of the slab bottom surface; $\theta 1$ - temperature of the slab top surface; I - shorter dimension of the floor design zone; $\mathrm{h}$ - overall depth of composite slab.

Figure $9 \mathrm{~b}$ presents the comparison between the obtained relative deflection of slab in the central part and the limitation of simple design method resulted from the temperatures computed numerically.

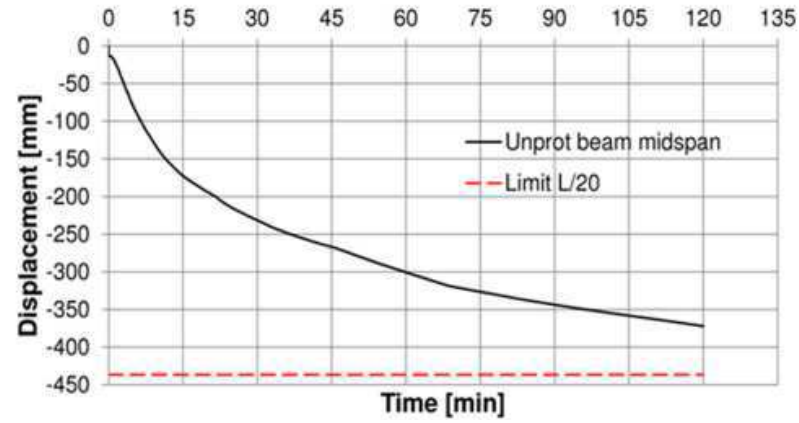

(a)

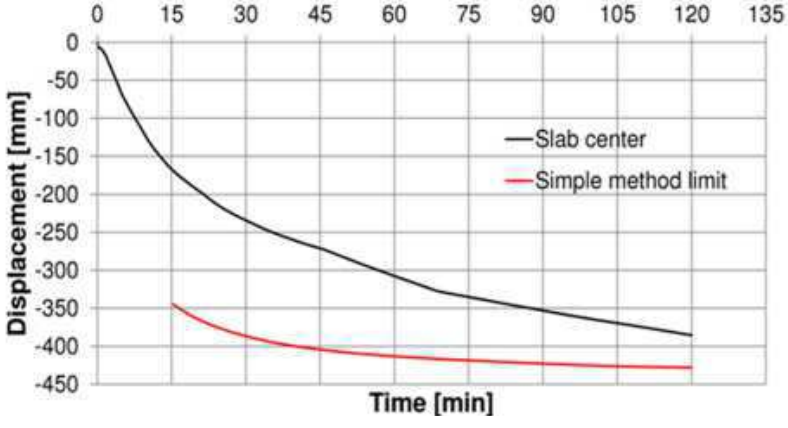

(b)

Figure 9: Relative deflection a) unprotected beam, b) central point of slab

The second condition of failure, related to the plastic strain of the reinforcement, is established in the report of The Steel Construction Institute [18] at a value of $5 \%$. Fig. 10 represents the maximum strains of the reinforcement at the support of the slab and in the central part of the slab where the program results show small values. In reality, the reinforcement strains are concentrated within the cracked area, and therefore results of the advanced models may be imprecise.

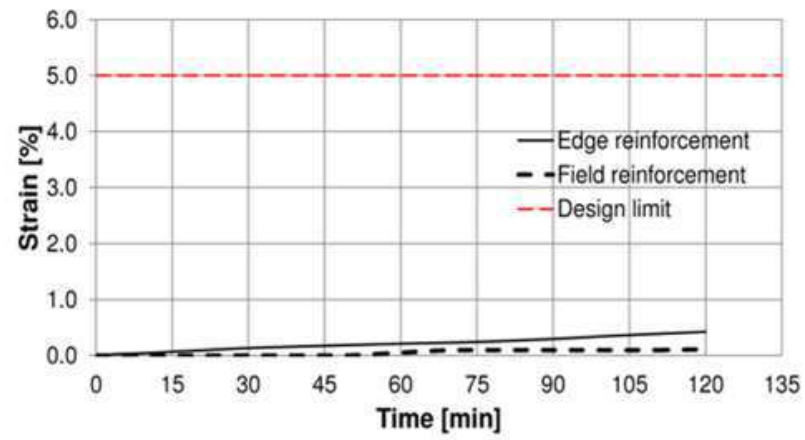

Fig.ure 10: Plastic strains of reinforcement

\section{CONCLUSION}

A benchmark for a composite slab in fire conditions was created, by describing a step-by-step procedure for a thermo-mechanical analysis within the general purpose FEM computer code Abaqus. The benchmark, based on a real scale fire test, contains simplified input data, in order to produce an accessible example. The procedure used in Abaqus was validated with the experimental results from the fire test, by means of the same numerical model, for which a complete input data was considered, with all the necessary parameters to be accounted for a thermomechanical numerical analysis of a structure in fire conditions. 


\section{ACKNOWLEDGEMENTS}

This publication was supported by the European social fund within the framework of realizing the project „Support of inter-sectoral mobility and quality enhancement of research teams at Czech Technical University in Prague“, CZ.1.07/2.3.00/30.0034.

\section{REFERENCES}

1) ABAQUS. (2011)ABAQUSDocumentation 6.11, Providence, RI, USA: Dassault Systèmes.

2) ANSYS. (2008) ANSYS $®$ Academic Research, Release 14.0.

3) /22/ Bailey, C.G. and Moore, D.B. (2000) The structural behaviour of steel frames with composite floorslabs subject to fire: Part 1:Theory. The Structural Engineer, 78 (11), 19-27.

4) Both, I., Wald, F. and Zaharia, R. (2015) Design issues of thermal induced effects and temperature dependent material properties in Abaqus, 7th International Conference on Materials Characterisation VII, 22-24 May 2015, Valencia, France.

5) C.E.N. (2002) EN 1991-1-2, Eurocode 1: Actions on structures - Part 1-2: General actions Actions on structures exposed to fire, Brussels.

6) C.E.N. (2004) EN 1992-1-2, Eurocode 2: Design of concrete structures - Part 1-2: General rules - Structural fire design, Brussels.

7) C.E.N. (2004) EN 1994-1-2, Eurocode 4 - Design of composite steel and concrete structures - Part 1-2: General rules - Structural fire design, Brussels.

8) C.E.N. (2005) EN 1993-1-2, Eurocode 3: Design of steel structures - Part 1-2: General rules - Structural fire design, Brussels.

9) Celik, I.B. (2008) Procedure for Estimation and Reporting of Discretization Error in CFD Applications. Journal of Fluids Engineering. 130(7), DOI 10.1115/1.2960953.

10) http://dictionary.reference.com/browse/benchmark, retrieved on November 22nd 2014.

11) Franssen, J.-M. (2005) Safir-A thermal/structural program modelling structures under fire. Engineering Journal, 42(3), 143-158.

12) Gillie, M. (2009) Analysis of heated structures: Nature and modelling benchmarks. Fire Safety Journal, 44 (5), 673-680.
13) Huang, Z., Burgess, I.W. and Plank, R.J. (1999) The influence of shear connectors on the behaviour of composite steel-framed buildings in fire. Journal of Constructional Steel Research, 51 (3), 219-237.

14) Kruppa, J. and Zhao, B. (1995) Fire resistance of composite beams to Eurocode 4 Part 1.2. Journal of Constructional Steel Research, 33 (1), 51-69.

15) Kwasniewski, L. (2013) Application of grid convergence index in FE computation, Bulletin of the Polish Academy of Sciences, March, 123-128.

16) MACS+, (2014) RFCS project "Membrane action in fire design of composite slab with solid and cellular steel beams - valorisation" (MACS+). Available: http://www.macsfire.eu/.

17) Stadler, M. (2012) Design of Composite Slab Systems in Case of Fire Using Simplified Finite Element Analyses. Ph.D. Thesis, Technical University in Munich.

18) The Steel Construction Institute. (2003) Design recommendations for composite steel framed buildings in fire. Part of final report for ECSC project 7210 PA, PB, PC, PD112.

19) Vulcan. (2014) [Online], Available: http://www. vulcan-solutions.com/ [2 November 2014].

20) Wald, F., Burgess, I., Kwasniewski, L., Horova, K. and Caldova, E. (ed.). (2014) Benchmark studies-Verification of numerical models in fire engineering, Prague: CTU Publishing House.

21) Zaharia, R., Vulcu, C., Vassart, O., Gernay, T. and Franssen, J.-M. (2013) Numerical analysis of partially fire protected composite slabs. Steel and Composite Structure, 14(1), 21-39.

22) Zhao, B., Roosefid, M. and Vassart, O. (2008) Full scale test of a steel and concrete composite floor exposed to ISO fire, Structures in fire (Proceedings of the Fifth International Conference), 28-30 May 2008, Singapore.

23) Zhao, B. and Roosefid, M. (2010) Experimental and numerical investigations of steel and concrete composite floors subjected to ISO fire Condition, Structures in fire (Proceedings of the Sixth International Conference), 2-4 June 2010, East Lansing, USA.

Paper sent to revision: 04.07.2015.

Paper ready for publication: 28.05.2016. 